\title{
MEETING ANNOUNCEMENT TO JOURNALS
}

The Second International Symposium on Innovative Numerical Analysis in Applied Engineering Science will be held June 16-20, 1980 at the Ecole Polytechnique de Montreal in Montreal, Canada. Papers are solicited in all areas of engineering science such as solid and fluid mechanics, electrical engineering, acoustic, etc. with emphasis on "non-standard" numerical analysis. Papers on innovative numerical analysis which emphasize technology transfer topics, hybridization of analysis methods and 'new' technology are strongly encouraged.

Extended abstracts of approximately 1000 words, in French or English, are required by March 15, 1979. Final accepted papers of up to 10 pages will be required by Dec. 15,1979 for publication in the symposium proceedings. Five copies of each abstract should be sent to

Dr. A. Chaudouet (Europe)

CETIM

Boite Postale No 67

60304 Senlis, Cedex, France

or to

Dr. T. Cruse

Pratt and Whitney Aircraft

East Hartford, Conn. 06108, U.S.A. 